\title{
Dissociative and Sympathomimetic Toxicity Associated with Recreational Use of 1-(3-Trifluoromethylphenyl) Piperazine (TFMPP) and 1-Benzylpiperzine (BZP)
}

\author{
David M. Wood, MDa, Jenny Button, DipFMS ${ }^{b}$, Satnam Lidder, MDa, John Ramseyc, \\ David W. Holt, PhD ${ }^{b}$, Paul I Dargan, FRCPEa
}

aGuy's and St Thomas' Poisons Unit, Guy's and St. Thomas' NHS Foundation Trust, London, UK

bAnalytical Unit, St George's, University of London, London, UK

c TICTAC Communications Ltd, St. George's, University of London, London, UK

\begin{abstract}
Introduction: There is emerging evidence of increasing use of legally available synthetic compounds as recreational drugs. While there are some changes to legislation relating to these synthetic compounds, often the emergence of the agents outpaces the effect of the legislation to curb their use, and the legal status of these agents may change as more information on their toxicity becomes known. TFMPP [1-(3-trifluoromethylphenyl) piperazine] was initially temporarily controlled under Schedule I of the Controlled Substances Act in 2002 in the US, but following further review and lack of published information on toxicity, it was removed from this control in 2004. In addition, there are very few "user reports" of effects when TFMPP is taken alone or in combination with BZP [1-benzylpiperazine].

Case reports: Three patients presented to our emergency department after ingesting 4 tablets thought to be 3,4-methylenedioxyN-methylamphetamine (MDMA, street name "Ecstasy") over the course of an evening. They presented with dissociative-type symptoms, nausea, and signs consistent with sympathomimetic toxicity. All 3 improved with conservative management and observation, within 12 hours of presentation. Serum analysis demonstrated the presence of TFMPP and BZP at concentrations of $263 \pm 5.8 \mathrm{ng} / \mathrm{mL}$ (range 260-270 ng/mL) and $46.7 \pm 15.3 \mathrm{ng} / \mathrm{mL}$ (range 30-60 ng/mL), respectively. No other recreational drugs were detected in an extended toxicological screen of blood and urine samples.

Discussion: This is the first case series of confirmed toxicity associated with recreational use of TFMPP in combination with BZP, with clinical features not consistent with BZP toxicity. In our view, the current legal status of TFMPP should be reviewed.
\end{abstract}

\section{INTRODUCTION}

Recreational drug use is common throughout the world, although there are differences in individual drug use between countries [1].
There is also emerging evidence of increasing use of legally available synthetic compounds, sold via the Internet, on the street or by recreational drug dealers, as legal compounds or passed off as

Keywords: 1-(3-trifluoromethylphenyl) piperazine, TFMPP, 1-Benzylpiperzine, BZP, recreational drugs, toxicity, dissociative symptoms This case series has been presented (but not published) as part of a larger series of "novel" recreational drugs at the 6th Asia Pacific Association of Medical Toxicology (APAMT) meeting in Bangkok, Thailand.

Note: David Wood and Paul Dargan have acted as scientific advisors to the UK Advisory Council on the Misuse of Drugs (ACMD) and the European Monitoring Centre for Drugs and Drug Addiction (EMCDDA).

There was no outside funding of any kind used for this study.

Corresponding Author: David Wood, MD, Guy's and St Thomas' Poisons Unit, Avonley Road, London, SE14 5ER, UK. Email: David.Wood@gstt.nhs.uk 
other known controlled drugs such as Ecstasy (3,4-methylenedioxy-N-methylamphetamine (MDMA)) or amphetamine [2]. The family of piperazine drugs is among some of the most commonly sold synthetic legal recreational drugs [3]. Within this family of drugs, 1-benzylpiperazine (BZP) was temporarily controlled under Schedule I of the Controlled Substances Act in the US in 2002, and following further review permanently controlled in 2004 [4]. Its legal status has now been under review in other areas of the world, and it has now been controlled throughout the European Union following a review by the European Monitoring Centre for Drugs and Drug Addiction (EMCDDA) [5]. However, there are other members of the piperazine family of drugs, such as 1-(3-trifluoromethylphenyl) piperazine (TFMPP), 1-(3-chlorophenyl)piperazine (mCPP), and 4-methoxyphenylpiperazine (MeOPP), which are often used in combination with BZP to enhance or alter its clinical effects [6].

There are no previously published reports in the medical literature relating to the toxicity of TFMPP when taken alone, and there are very few "user experiences" of TFMPP alone, since it is usually purchased and taken in combination with BZP $[7,8]$. These reports suggest that TFMPP has limited effects when taken on its own, but they also acknowledge that it can cause a prolonged "hangover-type" effect compared to other piperazines. In addition, there are no published data on the toxicity of the combined use of TFMPP and BZP. In animal models, it has been shown to produce aversive effects rather than causing selfadministration [9]. This is likely to limit its acceptability as a recreational drug, which may explain some of the decisions not to market TFMPP alone as an illicit drug. We report here a case series of 3 patients who presented with both sympathomimetic toxicity and dissociative-type symptoms following ingestion of what they believed were MDMA tablets but whom, on toxicological screening, had in fact ingested a combination of TFMPP and BZP.

\section{CASE SERIES}

\section{Case One}

An 18-year-old male with no significant past medical history presented to the emergency department (ED) feeling generally unwell following ingestion of 4 tablets, thought to be Ecstasy, and purchased from 4 different dealers within a single club venue. Following ingestion of the first 3 tablets, he developed a "high," but after ingestion of the fourth tablet he felt nauseated, generally unwell and weak, and developed dissociative symptoms, described as "a feeling of being in another world." On arrival in the ED he was agitated with bruxism. He had features of sympathomimetic toxicity with dilated pupils, tachycardia (127 bpm), inducible clonus (2-3 beats at ankles) with normal temperature $\left(35.9^{\circ} \mathrm{C}\right)$. ECG on presentation showed sinus tachycardia, but was otherwise normal. He was admitted overnight for observation and treated with IV fluids (1 L $0.9 \% \mathrm{NaCl}$ solution) and $5 \mathrm{mg}$ IV diazepam. The following morning, his symptoms had settled and he was discharged home with no long-term sequelae. He received advice concerning recreational drug use.

\section{Case Two}

A second 18-year-old male, also with no significant past medical history, apart from recurrent recreational use of Ecstasy, presented to the ED with agitation and anxiety following ingestion of 4 tablets, again thought to be Ecstasy, from the same 4 dealers within the same club venue as the previous case. He described dissociative-type symptoms, including a feeling as though "his insides had stopped working" since ingestion of the tablets. On examination he was agitated with bruxism. He had features of sympathomimetic toxicity with dilated pupils, tachycardia (126 bpm), marked inducible clonus (2-3 beats at ankles), but normal tone and reflexes, with a normal temperature $\left(36.5^{\circ} \mathrm{C}\right)$. ECG on presentation showed sinus tachycardia, but was otherwise normal. He was admitted overnight for observation and treated with IV fluids (1 $\mathrm{L} 0.9 \% \mathrm{NaCl}$ solution) and a total of $10 \mathrm{mg} \mathrm{PO}$ diazepam. The following morning, his symptoms resolved and he was discharged home with no long-term sequelae and was given advice concerning recreational drug use.

\section{Case Three}

A 19-year-old male, with a history of mild asthma, presented with the above 2 patients, again following ingestion of 4 tablets thought to be Ecstasy from the same 4 dealers within the same club venue as the previous 2 cases. He presented with nausea and vomiting, feeling generally unwell, unable to walk properly, and again with dissociative-type symptoms. On examination he was coherent but was very talkative. He had features of mild sympathomimetic toxicity with dilated pupils, mild tachycardia (101 bpm), no inducible clonus, and normal temperature $\left(36.0^{\circ} \mathrm{C}\right)$. ECG on presentation showed sinus rhythm. He was admitted overnight for observation and treated with IV fluids (1 L $0.9 \%$ $\mathrm{NaCl}$ solution). Again, on the following morning, he was clinically well, without symptoms; he was discharged home with no long-term sequelae and was given advice concerning recreational drug use.

\section{TOXICOLOGICAL SCREENING}

Informed consent was obtained from all 3 patients for toxicological screening of blood and urine samples to be undertaken by the Forensic Toxicology Services at St. Georgeís, University of London, UK. Routine toxicological analysis of both specimens using full scan electron ionization gas chromatography-mass spectrometry (GC/MS) after liquid/liquid extraction, identified the presence of TFMPP and BZP in all 3 patients. No MDMA was detected in any of the patients. The mean serum concentrations of BZP and TFMPP were $263 \pm 5.8 \mathrm{ng} / \mathrm{mL}$ (range 260-270 $\mathrm{ng} / \mathrm{mL}$ ) and $46.7 \pm 15.3 \mathrm{ng} / \mathrm{mL}$ (range $30-60 \mathrm{ng} / \mathrm{mL}$ ), respectively. Cannabinoids were detected in the urine of 1 patient, indicating probable recent use; no other recreational drugs were detected using a broad toxicology screen in blood and urine in all 3 patients. The only other drugs detected were diazepam in cases 1 and 2, related to in-hospital use of diazepam in both patients. 


\section{Discussion}

We have described here a case series of 3 patients who self-reported ingestion of MDMA, but developed atypical sympathomimetic symptoms requiring hospital observation. Subsequent toxicological screening detected a combination of 1-Benzylpiperazine (BZP) and 1-(3-trifluoromethylphenyl) piperazine (TFMPP).

$\mathrm{BZP}$ is recognized to have clinical effects, both desired and toxic, that are similar to amphetamines, while the combination of BZP with TFMPP is associated with more MDMA ("Ecstasy")-like effects in animal models [10;11]. TFMPP is a nonselective serotonergic agonist, thought when used in combination with BZP to provide a mood-elevating and hallucinogen-like effect, whereas the BZP provides a "stimulatory effect" [12-14]. Animal studies have shown that TFMPP given alone leads to increases in 5-HT concentrations only, whereas the 1:1 combination of BZP/TFMPP at a dose of $3 \mathrm{mg} / \mathrm{kg}$ results in increases in both 5 -HT and dopamine, similar to that seen with MDMA [10]. In addition, studies in mice have further supported the potential hallucinogenic effects of TFMPP in comparison to the stimulatory effects of BZP [11]. There have also been reports of the possibility of synergistic toxicity of the combination of BZP and TFMPP, with an increased risk of seizures at high combined doses in animal models [10]. However, it is difficult to ascertain whether this is due to the combination of these agents, as BZP itself is associated with seizures [15]. These studies support the hypothesis that the dissociative-type symptoms seen in our patients were most likely due to the TFMPP that had been ingested. Although BZP is now controlled in most parts of the developed world, there is still the potential for it to be supplied illegally, either through recreational drug dealers misrepresenting it as MDMA or amphetamines, or in misrepresented "BZP-free products," that in fact still contain BZP [2]. The legal status of TFMPP is currently not consistent. In the US, it was temporarily controlled under Schedule I of the Controlled Substances Act in 2002, but following further review it was removed from this control in 2004; currently it is legally available, although it is still controlled within Hawaii [16]. It is only classified as a controlled drug in Australia and in parts of the European Union (Belgium and Greece at the time of writing) [16].

In the cases reported here, the patients believed that they had ingested 4 tablets containing MDMA over the course of the evening. They developed both sympathomimetic and dissociative toxicity, and subsequent toxicological screening detected the presence of both BZP and TFMPP. Dissociative-type symptoms are not typical of previous reports of BZP toxicity [2,15], therefore it is likely that the cause of these symptoms was the TFMPP taken in combination with the BZP. Previously, we have reported that although routine toxicological screening is not normally undertaken in patients with recreational drug toxicity, in unusual presentations the use of toxicological screening is able to detect novel drugs $[2,17,18]$.

In our view there is a need for a more systematic approach to toxicological screening in centers seeing large numbers of patients with recreational drug toxicity in order that emerging novel recreational drugs can be detected and the degree of toxicity associated with their use recorded. Other authors have also supported the use of more systematic toxicological screening in patients with recreational drug toxicity to determine evolving epidemiological trends in recreational drug availability, use, and toxicity [6]. The data obtained would provide legislative authorities with more precise information on which they could base decisions on whether to alter the legal status of novel and emerging drugs.

The authors have no potential financial conflicts of interest to report. Conflicts of interest were disclosed previously.

\section{REFERENCES}

1. United Nations Office on Drugs and Crime. [webpage on the Internet]. World Drug Report 2007 [cited 2008 Aug 20]. Available from: http://www.unodc.org/pdf/research/wdrO7/WDR_ 2007.pdf

2. Wood DM, Dargan PI, Button J, Holt DW, Ovaska H, Ramsey J, et al. Collapse, reported seizure-and an unexpected pill. Lancet 2007;369:1490.

3. Sheridan J, Butler R, Wilkins C, Russell B. Legal piperazine-containing party pills-a new trend in substance misuse. Drug Alcohol Rev. 2007;26:335-343.

4. Drug Enforcement Administration. Schedules of controlled substances; placement of 2,5-dimethoxy-4-(n)-propylthiophenethylamine and N-benzylpiperazine into Schedule I of the Controlled Substances Act. Final rule. Fed Regist 2004:69; 12794-12797.

5. European Monitoring Centre for Drugs and Drug Addiction [webpage on the Internet]. New Commission proposal to strengthen control of synthetic drug BZP press release [updated 2007 Jul 17; cited 2008 Aug 20]. Available from: http://europa.eu/rapid/pressReleasesAction.do? reference $=I P / 07 / 1103$ $\&$ format $=H T M L \&$ aged $=$ O\&language $=E N \&$ guiLanguage $=e n$

6. Staack RF. Piperazine designer drugs of abuse. Lancet 2007;369:1411-1413.

7. Drug-Forum: The International Drugs Community discussion forum [webpage on the Internet]. TFMPP experiences [updated 2007 Dec 17; cited 2008 Aug 20]. Available from: http://www.drugs-forum.co.uk/forum/showthread. $p h p ? p=348422$

8. Everyonedoesit.com discussion forum [webpage on the Internet]. So is it worth trying TFMPP on its own? [updated 2006 Oct 20; cited 2008 Aug 20]. Available from: http://forum .everyonedoesit.co.uk/showthread.php?t=76307

9. Fantegrossi WE, Winger G, Woods JH, Woolverton WL, Coop A. Reinforcing and discriminative stimulus effects of 1-benzylpiperazine and trifluoromethylphenylpiperazine in rhesus monkeys. Drug Alcohol Depend 2005;77:161-168.

10. Baumann MH, Clark RD, Budzynski AG, Partilla JS, Blough BE, Rothman RB. N-substituted piperazines abused by 
humans mimic the molecular mechanism of 3,4-methylenedioxymethamphetamine (MDMA, or 'Ecstasy').

Neuropsychopharmacology 2005;30:550-560.

11. Yarosh HL, Katz EB, Coop A, Fantegrossi WE. MDMA-like behavioral effects of N-substituted piperazines in the mouse. Pharmacol Biochem Behav 2007;88:18-27.

12. Herndon JL, Pierson ME, Glennon RA. Mechanistic investigation of the stimulus properties of 1-(3-trifluoromethylphenyl)piperazine. Pharmacol Biochem Behav 1992;43: 739-748.

13. Schechter MD. Serotonergic-dopaminergic mediation of 3,4-methylenedioxymethamphetamine (MDMA, "ecstasy"). Pharmacol Biochem Behav 1988;31:817-824.

14. Campbell H, Cline W, Evans M, Lloyd J, Peck A. Comparison of the effects of dexamphetamine and 1-benzylpiperazine in former addicts. Eur J Clin Pharmacol 1973;6: 170-176.

15. Gee P, Richardson S, Woltersdorf W, Moore G. Toxic effects of BZP based herbal party pills in humans: a prospective study in Christchurch, New Zealand. N Z Med J 2005;118:U1784.

16. The Vaults of Erowid [webpage on the Internet]. TFMPP legal status. [updated 2008 Apr 01; cited 2008 Aug 20]. Available from: http://www.erowid.org/chemicals/tfmpp/tfmpp_law.shtml

17. Dargan PI, Button J, Hawkins L, Archer J, Ovaska H, Lidder S, et al. Detection of the pharmaceutical agent 'Glaucine' as a recreational drug. Eur J Clin Pharmacol 2008;64: 553-554.

18. Ovaska H, Viljoen A, Puchnarewicz M, Button J, Ramsey J, Holt DW, et al. First case report of recreational use of 2, 5-dimethoxy-4-chloroamphetamine (DOC) confirmed by toxicological screening. Eur J Emerg Med 2008; in press.

\section{BRIEF TOXICOLOGY COMMUNICATIONS}

\section{Head CT in Patient with Metabolic Acidosis}

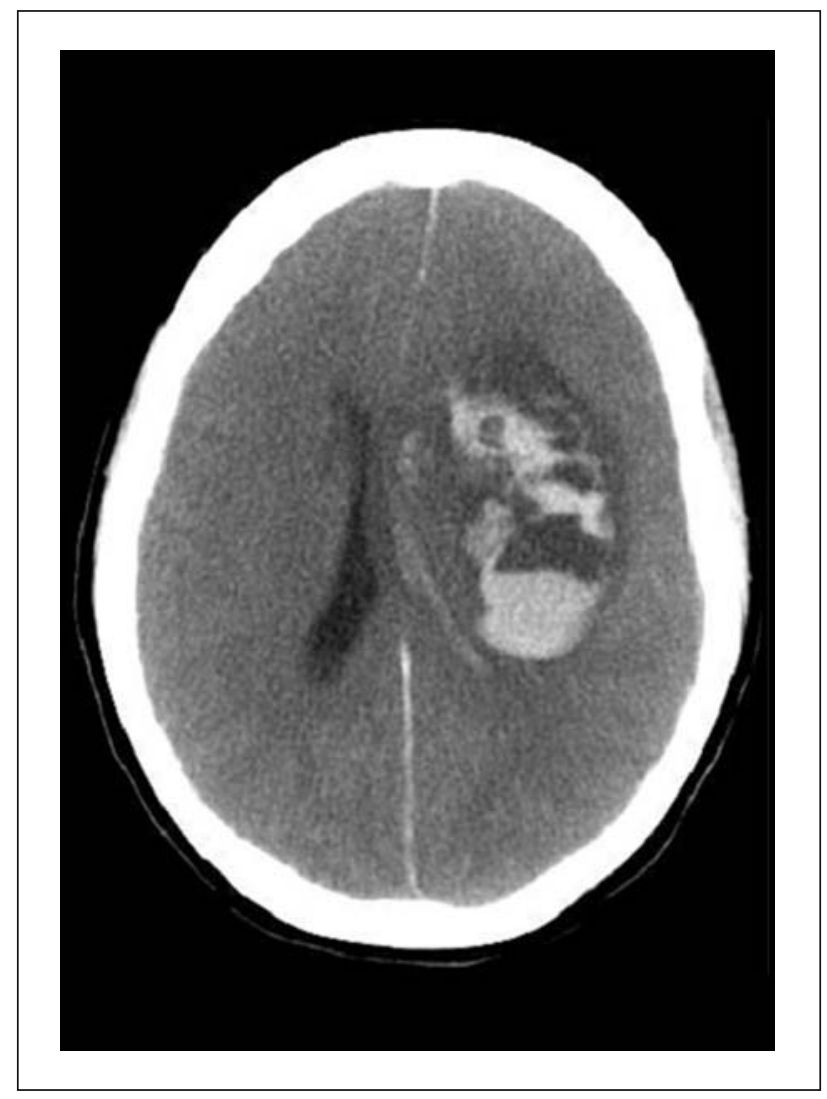

A patient presents with metabolic acidosis and this characteristic injury. Name the toxin. For the answer, see page 275 